\title{
DESAFIOS DA EQUIDADE DE GÊNERO NO SÉCULO XXI
}

\author{
José Eustáquio Diniz Alves \\ Fundação Instituto Brasileiro de Geografia e Estatística, Rio de Janeiro, Brasil
}

\begin{abstract}
Resumo: O objetivo deste artigo é discutir as limitações e os avanços nas relações de gênero ocorridas no Brasil e no mundo nos 70 anos desde a criação da Organização das Nações Unidas (ONU), em especial, desde a VI Conferência Mundial das Mulheres ocorrida em 1995, com base no relatório El Progreso de las Mujeres en el Mundo 2015-2016: Transformar las Economías para Realizar los Derechos elaborado pela ONU Mulheres, em 2015. Os dados, de modo geral, revelam conquistas substantivas das mulheres nas últimas sete décadas. Mas também mostram a existência de uma revolução incompleta, com manutenção da divisão sexual entre trabalho produtivo e reprodutivo, o que limita a autonomia e o empoderamento das mulheres na família e na sociedade.
\end{abstract}

Palavras-chave: Direitos humanos; equidade entre homens e mulheres; empoderamento feminino.

\section{Introdução}

O ano de 2015 marcou o septuagésimo aniversário da criação da Organização da Nações Unidas (ONU), os 20 anos da $4^{a}$ Conferência Mundial de Mulheres, ocorrida em Beijing, em 1995, e o lançamento dos Objetivos de Desenvolvimento Sustentável (ODS), válidos para o segundo quindênio (2015-2030) do século XXI. O mundo tem passado por grandes transformações econômicas, sociais, ambientais e culturais, sendo que o empoderamento das mulheres e a redução das desigualdades de gênero representam um passo essencial do progresso civilizatório, nesta etapa decisiva da história da humanidade. Nos últimos 70 anos houve um grande crescimento da população mundial (que passou de 2,3 bilhões de habitantes em 1945 para 7,3 bilhões em 2015), mas houve um incremento várias vezes maior da economia, que, mesmo de forma desigual e combinada, foi acompanhado de um aumento da renda per capita, redução das taxas brutas de mortalidade, elevação dos níveis de escolaridade, melhoria nas condições de habitação e ampliação e diversificação do consumo de bens e serviços (José Eustáquio Diniz ALVES, 2015).

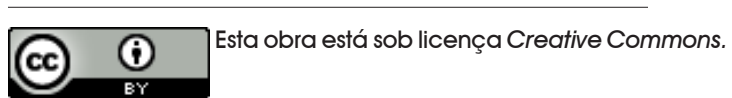


Houve melhoria das condições de vida das mulheres, mas isso ocorreu de forma diferenciada nas distintas áreas de atividade humana e não foi uniforme em termos nacionais e regionais. Porém, a boa notícia é que, no geral, as desigualdades de gênero se reduziram desde o fim da Segunda Guerra Mundial e, em especial, depois da $4^{a}$ Conferência Mundial de Mulheres. Isso fica claro no documento: EI Progreso de las Mujeres en el Mundo 2015-2016: Transformar las Economías para Realizar los Derechos (ONU MUJERES, 2015). O relatório mostra que desde a Declaração Universal dos Direitos Humanos, de 1948, passando pelas quatro Conferências da ONU sobre a situação das Mulheres, os diversos governos do mundo assumiram compromissos juridicamente vinculantes no sentido de respeitar, proteger e garantir os direitos humanos das mulheres, reconhecendo o vínculo entre o empoderamento feminino e a prosperidade econômica. Aliás, esta relação já tinha sido estabelecida, desde 1808, quando Charles Fourier disse: "o grau de emancipação das mulheres em uma sociedade é o termômetro geral através do qual se mede a emancipação geral" (Charles FOURIER, 1808, p. 97, tradução nossa).

Evidentemente, o caminho da emancipação feminina passa pela conquista de direitos substantivos e pela prevalência da igualdade de oportunidade entre os sexos na família e na sociedade. O empoderamento das mulheres - de todas as gerações - é um anseio cada vez maior das organizações da sociedade civil e um processo que avança nas diversas instâncias de poder dos Estados nacionais. Até os setores empresarias já perceberam a necessidade da incorporação da força produtiva feminina, reconhecendo as habilidades e talentos das mulheres para o dinamismo da economia, como mostra relatório do Fórum Econômico Mundial de Davos (WEF, 2009). É crescente o reconhecimento de que o progresso das sociedades é incompatível com a discriminação e a segregação de gênero e com a subutilização das capacidades da metade da população mundial. Mas se a igualdade de gênero, em geral, contribui para o progresso econômico, nem todo processo de desenvolvimento impulsiona a equidade entre homens e mulheres.

No mundo, nas últimas décadas, houve avanço na educação, com o aumento do número de meninas escolarizadas, elevação do número de mulheres no mercado de trabalho e maior presença nos espaços de poder e nas funções de liderança nas esferas pública e privada. As mulheres conseguiram maior acesso à propriedade e à herança de bens ao casar e ao divorciar-se etc. Entretanto, até agora, os ganhos foram parciais. Uma sociedade sem desigualdades sociais de gênero talvez possa ser atingida ao longo do século XXI, mas existem muitas barreiras a serem superadas no caminho, obstáculos que precisam ser reconhecidos e colocados no centro das políticas públicas, situando os direitos das mulheres no "coração de suas prioridades".

\section{Igualdade substantiva e direitos reais}

A Declaração Universal dos Direitos Humanos e os Tratados Internacionais que se seguiram - como a Convenção para a Eliminação de todas as Formas de Discriminação contra a Mulher (CEDAW) e o Pacto Internacional sobre Direitos Econômicos, Sociais e Culturais (PIDESC) -, foram fundamentais para criar as bases jurídicas da igualdade de direitos que podem ser demandadas na prática. Por exemplo, a Constituição Brasileira, de 1988, foi essencial para superar todas as leis discriminatórias existentes anteriormente no país e possibilitar um processo de revisão da legislação nacional. Mas a realidade é complexa e, mesmo diante de leis de igualdade de gênero, há desigualdades e práticas discriminatórias que persistem e continuam prejudicando as pessoas e os grupos sociais.

O relatório mostra que, para garantir a igualdade substantiva, é preciso atuar em três esferas inter-relacionadas: a erradicação das desvantagens socioeconômicas das 
mulheres; a luta contra os estereótipos, os estigmas e a violência; e o fortalecimento do poder de ação, de voz e de participação das mulheres. Os direitos humanos são universais, sinérgicos e indivisíveis, devendo atingir todas as pessoas, incluindo as áreas referentes à saúde, à educação, ao trabalho, à moradia, à liberdade de expressão, à organização e manifestação etc. Enfim, para garantir os direitos das mulheres é preciso avançar em políticas sociais com perspectiva de gênero, pleno emprego e trabalho decente e políticas macroeconômicas baseadas nos direitos humanos.

O caso brasileiro é interessante nesse aspecto, pois o país é conhecido por ter uma das legislações mais avançadas do mundo, mas, nem por isso, a igualdade de gênero foi alcançada na prática e em todas as esferas. Por um lado, as mulheres avançaram muito e até superaram os homens em algumas áreas, como na educação e na proteção social. As mulheres constituíam a maior parte da população analfabeta nos primeiros 450 anos da história do Brasil; porém, recentemente ultrapassaram os homens em todos os níveis educacionais, inclusive mestrado e doutorado. As mulheres brasileiras, atualmente, constituem cerca de $60 \%$ das titulações em grau universitário. A desigualdade de gênero, na educação, é reversa e tem se ampliado além do esperado. As mulheres são maioria das pessoas registradas no Cadastro Único que permite o acesso da população de baixa renda a vários programas sociais do Governo Federal. Também são maioria entre as pessoas que recebem benefícios da previdência social (sendo que a legislação atual favorece a aposentadoria feminina com 5 anos de antecedência em relação à masculina).

Por outro lado, as mulheres brasileiras continuam apresentando menores taxas de participação no mercado de trabalho, maiores níveis de informalidade nas relações trabalhistas e recebendo salários sistematicamente mais baixos que os dos homens. Embora as desigualdades tenham diminuído ao longo das últimas décadas, o ritmo de redução do hiato de gênero tem sido muito lento ou até ficado estagnado. Contribui, para esse fato, não apenas as discriminações inerentes ao mercado de trabalho, mas também as permanências culturais e sociais da divisão sexual entre trabalho produtivo e reprodutivo e as dificuldades práticas e institucionais de conciliação entre família e emprego, como veremos mais à frente.

\section{Pleno Emprego, Trabalho Decente e os ODS}

Pleno Emprego e Trabalho Decente é a principal bandeira da Organização Internacional do Trabalho (OIT). Evidentemente, essa bandeira deveria ser implementada sem qualquer discriminação de gênero. Porém, o relatório El Progreso de las Mujeres en el Mundo 2015-2016 mostra que, no mundo, entre 1990 e 2013, houve uma pequena redução das taxas de atividade de homens e mulheres e uma quase estagnação da desigualdade de gênero. As taxas de atividade masculinas caíram de 81 para $77 \%$ e as taxas femininas diminuíram de 52 para $50 \%$. A diferença entre as taxas masculinas e femininas era de 29 pontos em 1990 e caiu ligeiramente para 27 pontos em 2013. Mas a média mundial não retrata as diferenças regionais (ONU MUJERES, 2015).

As menores taxas de atividade das mulheres (em torno de $20 \%$ ) e as maiores desigualdades estavam no Médio Oriente e no Norte da África (MENA), com hiato de gênero acima de 50 pontos. Em seguida, os piores indicadores de atividade feminina e de desigualdade de gênero encontravam-se no Sul da Ásia - que inclui a Índia. Já as maiores taxas de atividade feminina (acima de 60\%) e os menores hiatos de gênero (em torno de 16 pontos) estavam no Leste Asiático e na África Subsariana. A América Latina e Caribe (ALC) tinham taxas de atividades de $82 \%$ para os homens e $40 \%$ para as mulheres em 1990 , passando para $80 \%$ para os homens e $54 \%$ para as mulheres em 2013 . As mulheres latinoamericanas foram as que mais reduziram o hiato de gênero (de 42 pontos para 26 pontos 
de diferença) no período, embora estando bem atrás dos níveis de atividade do Leste Asiático e da África Subsariana. Contudo, há indicações recentes de que os avanços femininos no mercado de trabalho foram interrompidos na região.

No Brasil - maior país da ALC - as mulheres conquistaram taxas crescentes de atividade laboral entre 1950 e 2012. Entretanto, as taxas de atividade começaram a cair a partir de 2012, segundo os dados da Pesquisa Mensal de Emprego, e a partir de 2013, segundo os dados da Pesquisa Nacional por Amostra de Domicílios Continua (PNAD Contínua), ambas do IBGE (2016). A crise no mercado de trabalho se acentuou em 2015 e deve se aprofundar em 2016. As projeções indicam que o Brasil deve ter, em 2020, taxas de atividade menores para o caso dos homens e uma estagnação para as taxas femininas. Ou seja, parece que as diversas regiões do mundo devem passar por uma conjuntura menos favorável no próximo quindênio (2015-2030) em relação ao que ocorreu nos últimos 70 anos. Todavia, o Objetivo 8, dos ODS pretende: "Promover o crescimento econômico sustentado, inclusivo e sustentável, emprego pleno e produtivo, e trabalho decente para todos", e a meta 8.5 estabelece que: "Até 2030, alcançar o emprego pleno e produtivo e trabalho decente todas as mulheres e homens, inclusive para os jovens e as pessoas com deficiência, e remuneração igual para trabalho de igual valor" (ONU, 2015, p. 41).

Evidentemente vai ser muito difícil colocar em prática o item 8 dos Objetivos de Desenvolvimento Sustentável e suas metas específicas. O relatório EI Progreso de las Mujeres en el Mundo 2015-2016 considera que o trabalho com remuneração digna e com proteção da legislação trabalhista é uma condição fundamental para a equidade de gênero, mas reconhece as dificuldades para viabilizar este direito na prática nos próximos anos:

Cierto es que este tipo de trabajo continúa escaseando y que las políticas económicas en todas las regiones se ven incapaces de crear un número suficiente de puestos de trabajo decentes para quienes los necesitan. Además, las oportunidades disponibles para las mujeres se ve limitada por los estereotipos de género y de las prácticas discriminatorias, tanto en el seno de los hogares como en el mercado laboral. Como resultado de ello, la inmensa mayoría de las mujeres sigue trabajando en empleos inseguros e informales (ONU MUJERES, 2015, p. 14).

O relatório considera que a coordenação das políticas em escala mundial é uma condição chave para criar um ambiente macroeconômico favorável à realização dos direitos das mulheres. Contudo, ressalta que o sistema de governança global agudiza negativamente, ao invés de mitigar, o viés de gênero das políticas macroeconômicas. Se essa constatação já era verdadeira para o quindênio 2000-2015, o quadro deve se agravar no quindênio 2015-2030, pois, com o crescente endividamento internacional e o fim do ciclo do boom das commodities, a economia global deve crescer menos e os países do Sul Global serão os mais afetados.

A consultoria Mackinsey, em relatório recente, mostrou que a dívida da economia global aumentou de US\$ 87 trilhões no quarto trimestre de 2000 para US\$ 199 trilhões no segundo trimestre de 2014. Em proporção do PIB, a dívida total atingiu 286\%, em 2014 (MACKINSEY, 2015). Diversos economistas ligados ao sistema financeiro (como Larry Summers, que foi secretário do Tesouro dos Estados Unidos) falam em "estagnação secular", como uma etapa de baixo crescimento da economia internacional. $O$ Banco Mundial fala em "lerdeza estrutural". E o Fundo Monetário Internacional (FMI) alertou, no início de outubro de 2015, em reunião realizada em Lima, Peru, sobre a possibilidade de uma fuga abrupta e expressiva de capital dos países ditos "emergentes". Assim, num contexto de menor crescimento econômico e de maior concorrência capitalista, não será fácil manter e ampliar as conquistas femininas (George MARTINE; José Eustáquio Diniz ALVES, 2015). 


\section{Formular políticas sociais idôneas para as mulheres}

Se o modelo capitalista de produção fosse capaz de gerar inclusão econômica e justiça social, garantindo pleno emprego, trabalho decente, remuneração justa (salário igual para função igual) e se o livre mercado fosse neutro em relação às questões de gênero, raça/cor, geração etc., então o papel do Estado seria secundário ou até irrelevante.

Mas o mercado - que pode ter papel relevante na busca da eficiência econômica -, em geral, concentra a riqueza, gera desigualdade e exclusão social. Nesse sentido, as políticas públicas nas sociedades democráticas precisam atuar no sentido de garantir o mínimo de igualdade de oportunidade para as pessoas e os diferentes grupos sociais, além de garantir acesso à proteção social para as pessoas e às parcelas da população excluídas. Ou seja, é preciso combinar políticas universais com políticas focalizadas, como mostra o relatório El Progreso de las Mujeres en el Mundo 2015-2016:

Para hacer realidad los derechos económicos y sociales de todas las personas, lo ideal es adoptar un enfoque integral con respecto a la política social, que combine el acceso universal a los servicios sociales con la protección social a través de sistemas de transferencia contributivos y no contributivos. (ONU MUJERES, 2015, p. 15).

Ao contrário de vários países do mundo que não garantem direito universal ao sistema previdenciário para as mulheres, pessoas com deficiência, idosos etc., o Brasil, depois da Constituição Federal de 1988, tem feito um esforço para uma cobertura universal. Mesmo sendo um contingente minoritário no mercado de trabalho, as mulheres brasileiras predominam entre as pessoas beneficiárias da previdência social - tanto entre as aposentadas quanto em relação às pensionistas. Somando-se as aposentadas e pensionistas, as mulheres eram 10,2 milhões em 2001 e passaram para 15,2 milhões em 2013 , enquanto os homens correspondiam a 8,1 milhões e 11,5 milhões, no mesmo período. O sistema previdenciário no Brasil tem um papel de mitigar algumas desigualdades do mercado de trabalho e é um fator importante para a redução da pobreza (José Eustáquio Diniz ALVES; Sônia CORREA, 2009)

Outra ação que tem importância para a redução das condições de pobreza no Brasil é o Programa Bolsa Família (PBF), que é uma política de transferência de renda com condicionalidades (TRC), criado em 2003. O Programa Bolsa Família tem como objetivo garantir o direito básico à alimentação e o exercício da cidadania por meio do acesso aos direitos à educação e à saúde (além de outros direitos complementares), contribuindo para que as famílias possam romper o ciclo da pobreza entre as presentes e as futuras gerações. De modo geral, havia consenso de que os recursos do PBF eram fundamentais para ajudar as famílias vivendo em situação de pobreza extrema e para garantir uma renda básica para as mulheres que são a grande maioria das beneficiárias titulares do programa. Atualmente, os baixos valores da transferência do PBF são questionados, pois, com a grande desvalorização cambial ocorrida no Brasil, em 2015, o valor de R\$ 77,00 (utilizados como critério de corte da linha de pobreza) representam menos de US\$ 1,00 por dia, o que, evidentemente, é insuficiente para aliviar a carga das demandas essenciais das famílias pobres.

O relatório El Progreso de las Mujeres en el Mundo 2015-2016 apresentou o PBF como exemplo de ação capaz de reduzir a desigualdade e melhorar a vida das mulheres. Contudo, há controvérsias sobre os impactos do PBF sobre a autonomia feminina. Os otimistas consideram que os recursos do Programa possibilitam um maior empoderamento feminino, pois a mulher passa a ter acesso a montantes financeiros regulares, o que aumenta sua capacidade de decisão e alocação em função das prioridades pessoais e coletivas. Os pessimistas consideram que, ao invés de promover a autonomia feminina, o PBF fortalece o papel 
tradicional da mulher como dona de casa e cuidadora do lar, jogando nas costas da família as responsabilidades estatais pelo combate à pobreza. As condicionalidades sobrecarregam os compromissos femininos. Além disso, o foco nas mulheres contribui para deixar de lado a responsabilidade masculina na reprodução, desconsiderando o fato de que em muitas famílias os homens são ausentes, passivos ou simplesmente omissos. A não responsabilização dos homens aumenta a carga de trabalho e responsabilidade das mulheres, em seu papel tradicional, e reduz sua mobilidade social. O relatório constata que:

En conjunto, las transferencias sociales y los servicios sociales pueden constituir una poderosa herramienta para corregir la desventaja socioeconómica que sufren las mujeres como consecuencia de sus responsabilidades de cuidados no remuneradas y de la desigualdad de oportunidades de empleo. (ONU MUJERES, 2015, p. 129).

De fato, a divisão sexual do trabalho provoca uma desigual distribuição do uso do tempo entre as atividades de produção e reprodução. Em geral, as mulheres são sobrecarregadas com os afazeres da reprodução (trabalho não remunerado), enquanto os homens possuem maior disponibilidade para as atividades da produção (trabalho remunerado). A questão que se coloca, em termos de políticas públicas, é como liberar as mulheres para o exercício do seu direito ao emprego remunerado, como comprometer os homens com a economia do cuidado, e como o Estado pode implementar políticas que favoreçam a conciliação entre trabalho e família.

Nesse sentido, o relatório considera fundamental focar em um piso de proteção social, como uma estratégia concreta para sua realização progressiva, pois, na ausência do poder público, os custos da solidariedade familiar, especialmente entre a população mais pobre, tende a sobrecarregar o trabalho feminino não remunerado:

En ausencia de un apoyo público adecuado, los hombres y las mujeres, en especial los que viven en hogares de bajos ingresos, se ven obligados a depender de las redes sociales informales. La dependencia de la familia, los parientes y la comunidad puede resultar profundamente problemática para las mujeres. Por un lado, las redes informales están estructuradas fundamentalmente en torno al trabajo doméstico y de cuidados no remunerado que realizan las mujeres. Por otro, es muy poco frecuente que se reconozcan y aborden adecuadamente las necesidades de apoyo de las propias mujeres, debido a las normas sociales dominantes y a las relaciones de poder entre los géneros (ONU MUJERES, 2015, p. 131).

Os serviços sociais são particularmente importantes para aliviar a carga de trabalho doméstico. O desenho das políticas públicas deve levar em conta os estereótipos e a violência de gênero, buscando reduzir os riscos que afetam as populações não masculinas. Os serviços sociais - como educação, saúde, moradia, água e saneamento básico - devem considerar as necessidades específicas das mulheres e das crianças, além de garantir o poder de ação, de voz e de participação das mulheres na elaboração e execução das políticas públicas.

\section{A janela de oportunidade demográfica e 0 empoderamento feminino}

Uma das maiores conquistas da história da humanidade, ocorrida em grande parte nos últimos 70 anos, foi a expressiva queda das taxas de mortalidade e o aumento da longevidade. Segundo a Divisão de População da ONU, a esperança de vida ao nascer, no quinquênio 1950-1955, era de 45,4 anos para os homens e de 48,3 anos para as mulheres (diferença de 3 anos a favor do sexo feminino). No quinquênio 2010-2015, a 
esperança de vida ao nascer dos homens subiu para 68,3 anos e a das mulheres subiu para 72,8 anos. Para o quinquênio 2025-2030, em termos globais, projeta-se uma esperança de vida ao nascer de 71,4 anos para os homens e de 75,9 anos para as mulheres (diferença de 4,5 anos entre os sexos). Em 80 anos, o ganho estimado foi de 26 anos de sobrevida dos homens e de 27,7 anos das mulheres. Ou seja, quando se trata da extensão do direito à vida, no mundo, existe uma desigualdade reversa de gênero, com as mulheres vivendo mais que os homens e conquistando diferenças crescentes ao longo das últimas décadas. Ter mais anos na fase adulta afeta positivamente o mercado de trabalho, a economia em geral, e as formas de organização social.

O relatório El Progreso de las Mujeres en el Mundo 2015-2016 não aprofundou, como seria conveniente, as especificidades globais e locais da demografia, mas colocou corretamente que tanto os países desenvolvidos quanto os países em desenvolvimento têm experimentado grandes mudanças nos padrões de formação de família, adiamento do matrimônio, aumento das taxas de coabitação, incremento das uniões de pessoas do mesmo sexo, elevação das taxas de divórcio, queda da fecundidade, crescimento dos domicílios unipessoais e envelhecimento da população. Contudo, há ainda diferenças significativas entre os diversos países e regiões do mundo.

Nos países mais desenvolvidos o processo de envelhecimento populacional já está mais avançado, a taxa de fecundidade está bem abaixo do nível de reposição e a razão de dependência demográfica é mais elevada. Os países em desenvolvimento e de renda média ainda estão na fase inicial de envelhecimento e a razão de dependência está em seus níveis mais baixos. Já os países mais pobres ainda possuem uma estrutura etária rejuvenescida, uma taxa de fecundidade bem acima do nível de reposição e uma razão de dependência ainda em declínio. Isso quer dizer que os países desenvolvidos já passaram pela fase conhecida como bônus demográfico, os países em desenvolvimento de renda média estão em plena fase do bônus e os países pobres ainda não chegaram no momento demográfico mais favorável.

Todo país que conseguiu aproveitar a janela de oportunidade demográfica se desenvolveu e conseguiu oferecer boas condições de vida para a população. $O$ aproveitamento do bônus demográfico feminino é essencial para os avanços do bemestar geral e para o empoderamento das mulheres. Isso acontece porque a queda das taxas de fecundidade e de mortalidade infantil permitem que as mulheres possam dedicar menos tempo às tarefas de reprodução e de cuidado dos filhos, passando a ter mais tempo para cuidar de si próprias e de se incorporar ao trabalho remunerado. Adicionalmente, o aumento da esperança de vida eleva o ciclo de vida produtivo da mulher e, juntamente com o aumento das taxas de escolaridade, aumenta o capital humano feminino. Nesse sentido, as mudanças demográficas e sociais reforçam as atividades produtivas e abrem novas oportunidades para os diversos membros da família.

O relatório mostra que a elite mais rica, correspondendo a $1 \%$ da população mundial, concentrava $40 \%$ dos ativos disponíveis e os níveis de desigualdade e vulnerabilidade, no seio de cada país e entre os países, segue uma tendência crescente. Essa constatação ganha relevância para a situação atual do Brasil e da América Latina, pois, com o fim do "super ciclo das commodities" houve uma mudança do quadro econômico que generalizou a crise fiscal dos diferentes Estados e várias conquistas obtidas na primeira década do século XXI estão sendo perdidas na segunda década, particularmente no ano de 2015 , marcado por uma recessão na região.

Portanto, as políticas públicas com enfoque de gênero devem atentar para as diferentes dinâmicas demográficas e para as desigualdades locais e globais de renda e riqueza, especialmente nas conjunturas de crise econômica. Atualmente, o envelhecimento 
populacional é um fenômeno crítico nos países desenvolvidos. Nos países em desenvolvimento de renda média, os desafios maiores estão na conquista do pleno emprego e trabalho decente, juntamente com políticas de conciliação de trabalho e família e apoio a uma melhor distribuição do uso do tempo entre os cônjuges. Nos países pobres e menos desenvolvidos, a redução da mortalidade materna e dos altos índices de gravidezes indesejadas ainda é um desafio básico. Políticas para garantir o acesso aos serviços universais de saúde reprodutiva são essenciais e possuem grande impacto de gênero, com o declínio da mortalidade infantil e o aumento da autonomia feminina.

\section{À guisa de conclusão}

O relatório El Progreso de las Mujeres en el Mundo 2015-2016 é um documento que analisa as transformações na economia, o progresso das mulheres e o que falta para a conquista de direitos e o alcance da equidade de gênero. Uma lacuna injustificada referese ao meio ambiente, pois é sabido que o progresso humano se deu às custas do regresso ambiental. A crise ecológica não é neutra quanto às relações de gênero. O ecofeminismo, por exemplo, considera que existe uma convergência entre a forma como o pensamento patriarcal vê as mulheres e a natureza, ou seja, a dominação das mulheres e a exploração da natureza são dois lados da mesma moeda na utilização dos "recursos naturais" sem custos, a serviço da acumulação de capital e da manutenção dos privilégios de todos os tipos e de todas as ordens.

Porém, mesmo de um ponto de vista antropocêntrico, a despeito das inúmeras dificuldades contemporâneas, nunca na história as condições econômicas, sociais e institucionais foram tão propícias à conquista da equidade de gênero. As transformações estruturais, institucionais e os diversos Tratados Internacionais com base nos direitos humanos, juntamente com o esforço já realizado pelos movimentos de mulheres, tornaram ilegítimas as assimetrias artificiais entre homens e mulheres e criaram uma base mínima para a construção de uma nova arquitetura social, alicerçada nos princípios da justiça e da ética, sem discriminações de sexo, idade, origem social, cor, orientação sexual e distinção de qualquer outra natureza.

O potencial de avanço rumo à igualdade substantiva é maior quando as reivindicações das mulheres e dos grupos organizados com base na equidade de gênero encontram receptividade nas diversas instâncias de poder e quando existem mecanismos de consulta que permitem as mulheres articular legitimamente suas reivindicações em termos políticos. A equidade de gênero é, essencialmente, uma questão de direito humano. Mas não deixa de ser também uma questão de desenvolvimento do progresso civilizatório. Porém, por conta das tarefas reprodutivas da vida social (cuidado da casa, das crianças, dos idosos, incapacitados etc.) muitas mulheres não progridem verticalmente nas carreiras e, em geral, ficam fora das instâncias mais elevadas do poder.

Para mudar essa realidade, a tática de curto prazo passa pela elaboração de "políticas de conciliação família-trabalho" e políticas afirmativas para romper com as barreiras que impedem o acesso feminino ao topo das estruturas de poder. Dessa forma, o êxito do movimento de mulheres depende das alianças que consigam forjar com outros movimentos em defesa da justiça social e da ampliação da democracia.

Em termos estratégicos, é necessário construir um caminho rumo à paridade na participação nos espaços de decisão política do Executivo e Legislativo, nos tribunais superiores do Judiciário e nas esferas mais elevadas de influência das empresas privadas. Geralmente, em condições de igualdade de oportunidades, as mulheres tendem a se sobressair, como acontece na área de educação, na maior parte do mundo. 
O escritor Vitor Hugo fez uma constatação histórica que vale para o processo de emancipação das mulheres: "Nenhum poder na Terra pode parar uma ideia cujo tempo chegou" (Vitor HUGO, 1878, p. 35, tradução nossa). Nesse sentido, o processo de aumento da autonomia feminina e de despatriarcalização da sociedade parece irreversível. A ideia básica do feminismo pode ser resumida em uma frase: Direitos iguais, autonomia e igualdade de oportunidade entre os sexos na família e na sociedade. Até agora as vitórias foram parciais. Uma sociedade sem desigualdades sociais de gênero é uma realidade que se vislumbra no horizonte e, com esforço, poderá ser atingida no século XXI.

\section{Referências}

ALVES, José Eustáquio Diniz. "Os 70 anos da ONU e a agenda global para o segundo quindênio (2015-2030) do século XXI”. Rev. Bras. Estud. Popul., São Paulo, vol. 32, n. 3, p. 587-598, 2015. Disponível em <http://www.scielo.br/scielo.php?script=sci_arttext\&pid=S0102$30982015000300587 \&$ Ing $=$ pt\&nrm $=$ iso $>$. Acesso em 10/02/2016

; CORREA, Sônia. "Igualdade e desigualdade de gênero no Brasil: um panorama preliminar, 15 anos depois do Cairo". In: ABEP, Brasil, 15 anos após a Conferência do Cairo, ABEP/UNFPA, Campinas, 2009, p. 121-223. Disponível em: <http://www.abep.nepo.unicamp. br/docs/outraspub/cairo15/Cairo15 3alvescorrea.pdf > . Acesso em: 10/02/2016.

FOURIER, Charles. Théorie des quatre mouvements et des destinées générales: prospectus et annonce de la découverte. France: Leipzig, 1808. Disponible en <http://catalogue. bnf.fr/ark:/12148/cb30454501s >. Accès: 10/02/2016.

HUGO, Victor. L'Histoire d'un crime: déposition d'un témoin. Paris: Ancienne Maison Michel Lévy Frères, 1877 [Calmann Lévy, éditeur]. Disponible en <https://archive.org/details/ histoireduncrim04hugogoog >. Accès: 10/022016.

IBGE. Pesquisa Nacional por Amostra de Domicílios Contínua Trimestral: 10 trimestre 2012 a $3^{\circ}$ trimestre 2015. Disponível em: <http://www.sidra.ibge.gov.br/bda/pesquisas/pnadc/ default.asp?o=27\&i=P>. Acesso em: 10/02/2016.

IBGE. Pesquisa Mensal de Emprego. Disponível em: <http://www.sidra.ibge.gov.br/bda/ pesquisas/pme/default.asp?o=21\&i=P>. Acesso em: 10/02/2016.

MARTINE, George; ALVES, José Eustáquio Diniz. "Economia, sociedade e meio ambiente no século 21 : tripé ou trilema da sustentabilidade?". Rev. Bras. Estud. Popul., São Paulo, vol. 32, n. 3, p. 433-460, 2015. Disponível em <http://www.scielo.br/scielo.php?script=sci arttext\&pid=S0102-30982015000300433\&lng=pt\&nrm=iso > . Acesso em: 10/02/2016.

MCKINSEY GLOBAL INSTITUTE. Debt and (not much) deleveraging. London: McKinsey Global Institute, February 2015. Available from: <http://www.mckinsey.com/insights/mgi > Access on: 10/02/2016.

ONU MUJERES. El Progreso de las Mujeres en el Mundo 2015-2016: Transformar las Economías para Realizar los Derechos. Nueva York, ONU Mujeres, 2015. Disponible en: $<$ http://progress.unwomen.org/en/2015/pdf/UNW_progressreport_es_10_12.pdf > . Acceso en: 10/02/2016.

ONU. Transformando Nosso Mundo: a Agenda 2030 para o Desenvolvimento Sustentável. Disponível em: <https://nacoesunidas.org/pos2015/agenda2030/>. Acesso em: 10/02/ 2016.

WEF - World Economic Forum. The Global Gender Gap Index (GGGI) 2009. Switzerland, 2009.

[Dossiê proposto em 6/07/2015, apresentado em 12/01/2016 aceito para publicação em 29/02/2016] 
The Challenges of Gender Equality in the Twenty-First Century

Abstract: The objective of this paper is to discuss the limitations and advances in gender relations that took place in Brazil and in the World in the last 70 years, since the creation of the United Nations Organization (UN) and, specially, since the Fourth World Conference on Women carried out in 1995, based on the report entitled Progress of The World's Women 2015-2016 Transforming Economies, Realizing Rights, elaborated by the UN Women in 2015. The data generally reveal substantive achievements of women in the last seven decades. But also show an incomplete revolution, maintaining the sexual division between productive and reproductive work, which limits the autonomy and empowerment of women in family and society.

Keywords: Human Rights; Gender Equality; Women's Empowerment.

638 Estudos Feministas, Florianópolis, 24(2): 629-638, maio-agosto/2016 